\title{
The repair of a type Ia endoleak following thoracic endovascular aortic repair using a stented elephant trunk procedure
}

\author{
Rui-Dong Qi, MD, Jun-Ming Zhu, MD, Yong-Min Liu, MD, Lei Chen, MD, Cheng-Nan Li, MD, \\ Xiao-Yan Xing, MD, and Li-Zhong Sun, MD
}

\begin{abstract}
Background: Type Ia endoleaks are not uncommon complications that occur after thoracic endovascular aortic repair (TEVAR). Because aortic arch vessels prevent extension of the landing zone, it is very difficult to manipulate a type Ia endoleak using an extension cuff or stent-graft, especially when the aortic arch is involved. Here, we retrospectively review our experience of surgical treatment of type Ia endoleak after TEVAR using a stented elephant trunk procedure.
\end{abstract}

Methods: From July 2010 to August 2016, we treated 17 patients diagnosed with a type Ia endoleak following TEVAR using stented elephant trunk procedure. The mean age of our patients was $52 \pm 8$ years. The mean interval between TEVAR and the open surgical repair was $38 \pm 43$ months.

Results: All cases of type Ia endoleak (100\%) were repaired successfully. There were no in-hospital deaths. One case required reintubation and continuous renal replacement therapy due to renal failure; this patient recovered smoothly before discharge. One other patient suffered a stroke and renal failure and did not fully recover following discharge, or follow-up. During follow-up, there were 3 deaths.

Conclusions: Acceptable results were obtained using a stented elephant trunk procedure in patients with a type Ia endoleak after TEVAR. This technique allowed us to repair the proximal aortic arch lesions, surgically correct the type Ia endoleak, and promote false lumen thrombosis in the distal aorta. Implantation of a stented elephant trunk, with or without a concomitant aortic arch procedure, is an alternative approach for this type of lesion. (J Thorac Cardiovasc Surg 2018;155:1391-6)

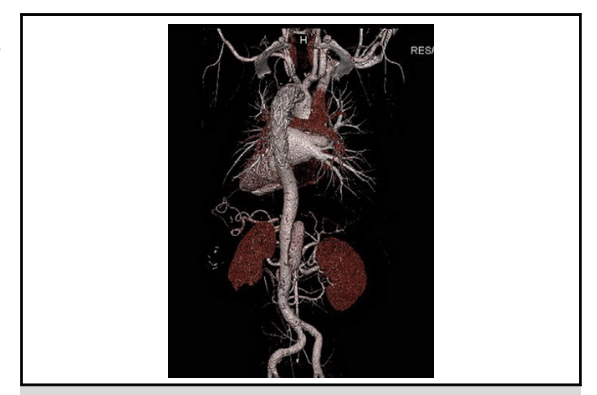

Postoperative computed tomography image reconstruction of type la endoleak repair.

\section{Central Message}

Use of the stented elephant trunk technique allowed us to repair the proximal aortic arch lesions, surgically correct the type Ia endoleak, and promote false lumen thrombosis in the distal aorta.

\section{Perspective}

Using a stented elephant trunk technique, we were able to surgically repair cardiac disease lesions and the proximal aortic arch, exclude or replace the aneurysm sac arising from endoleak, and promote thrombus formation in the distal aorta. This procedure, performed either with or without a concomitant procedure, is an effective surgical treatment for proximal type I endoleak after TEVAR.

See Editorial Commentary page 1397.
From the Beijing Aortic Disease Center, Beijing Institute of Heart, Lung and Blood Vessel Diseases and Beijing Anzhen Hospital, Capital Medical University, Beijing, China.

This study was supported by grants from the special research fund for public welfare from the National Health and Family Planning Commission of China (201402009) and the National Key Technology R\&D Program (2015BAI12B03).

Received for publication Aug 5, 2017; revisions received Oct 20, 2017; accepted for publication Nov 24, 2017; available ahead of print Jan 12, 2018.

Address for reprints: Jun-Ming Zhu, MD, Beijing Aortic Disease Center, Beijing Anzhen Hospital, Capital Medical University, 2 Anzhen Rd, Beijing 100029, China

(E-mail: anzhenzjm@163.com).

$0022-5223 / \$ 36.00$

Copyright (C) 2017 by The American Association for Thoracic Surgery

https://doi.org/10.1016/j.jtcvs.2017.11.088
Thoracic endovascular aortic repair (TEVAR) has become an alternative to open surgery for thoracic aortic disease to avoid the invasiveness associated with the latter technique. The long-term durability of TEVAR remains a concern, however. Complications related to endograft,

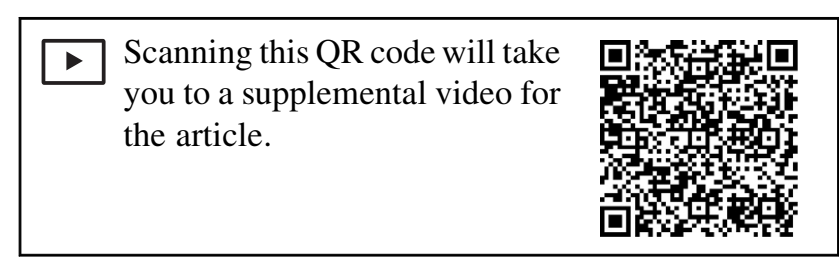




\section{Abbreviations and Acronyms \\ $\mathrm{CPB}=$ cardiopulmonary bypass \\ $\mathrm{CT}=$ computed tomography \\ LCCA $=$ left common carotid artery \\ LSCA $=$ left subclavian artery \\ SACP = selective antegrade cerebral perfusion \\ TEVAR $=$ thoracic endovascular aortic repair}

such as endoleak, stroke, and retrograde type A dissection, are not uncommon. ${ }^{1}$ The reported rate of reintervention following TEVAR is as high as $30.6 \%$ in patients with type B dissection enrolled in the International Registry of Acute Aortic Dissection ${ }^{2}$; another long-term study, covering a 20 -year period, reported a rate of $36.8 \%$.

The most common complication of TEVAR, endoleak occurs at a rate of $23.3 \%$ to $32.9 \%$ in patients with thoracic descending aortic disease undergoing TEVAR. ${ }^{3,4}$ Owing to the challenge of achieving a seal in the curved transverse aortic arch, thereby preventing damage to the aortic arch vessels, the repair of type Ia endoleak (ie, proximal endoleak) following TEVAR remains an intractable problem. To avoid high sac pressure, endovascular techniques can be performed in patients with type Ia endoleak to prevent aneurysm dilatation and rupture. However, an interventional method is not always technically feasible, particularly in patients with a type Ia endoleak with distal aortic arch involvement. In this study, we report our surgical experience in treating type Ia endoleak by implanting a stented elephant trunk, with or without a concomitant aortic arch procedure.

\section{METHODS \\ Patients}

Between July 2010 and August 2016, 17 of our patients (16 males, 1 female) with type Ia endoleak underwent a stented elephant trunk procedure via median sternotomy under hypothermic cardiopulmonary bypass (CPB) with selective antegrade cerebral perfusion (SACP) (Figure 1). This study was approved by the Institutional Review Board of Capital Medical University. The mean patient age was $50 \pm 8$ years (range, $41-68$ years); 14 of the 17 patients had a history of hypertension. The preoperative patient characteristics are summarized in Table 1.
All patients underwent TEVAR due to type B dissection. Fourteen of the 17 patients with primary TEVAR performed at other center were transferred to our center; the other 3 TEVAR procedures were performed by our own surgical team. Before surgery, a computed tomography (CT) scan was performed to confirm the presence of type Ia endoleak. The dissection extended into the abdominal aorta in 7 patients, and into the iliac artery in 10 patients. The mean diameter of the distal aortic arch was $59 \pm 26 \mathrm{~mm}$. The proximal edge of the endograft was proximal to the left subclavian artery (LSCA) origin in 2 patients, covered the LSCA origin in 7 patients, and was distal to the LSCA origin in 8 patients. Two patients underwent a second TEVAR procedure due to type Ia endoleak, both of which were unsuccessful. The mean interval between the primary TEVAR procedure and open surgical repair was $38 \pm 43$ months (range, 1-132 months).

\section{Surgical Technique}

All procedures were performed via a median sternotomy under $\mathrm{CPB}$ with SACP. The right axillary artery was isolated and used for CPB and SACP. The brachiocephalic vessels and the transverse arch were then dissociated and exposed. Generally, CPB was initiated by arterial cannulation of the right axillary artery and venous cannulation via the right atrium. The concomitant procedure (aortic root procedure or coronary artery bypass grafting) was performed during the cooling phase. Once the nasopharyngeal temperature reached $25^{\circ} \mathrm{C}$, the brachiocephalic vessels were clamped. Circulatory arrest was induced and the brain was perfused at approximately 5 to $10 \mathrm{~mL} / \mathrm{kg} /$ minute using SACP.

In patients undergoing only the stented elephant trunk procedure, the distal aortic arch was opened, and the proximal part of the stent-graft was removed. A 10- to 15-cm self-expandable stented graft (Cronus; Microport, Shanghai, China) was then implanted into the remaining interventional stent-graft. The proximal aortic segment was then anastomosed to the distal aorta using sutures, incorporating the remaining transected stent-graft and the stented elephant trunk. Once the anastomosis was complete, CPB was gradually resumed to normal flow, and rewarming started.

The surgical technique for patients undergoing implantation of a stented elephant trunk with transposition of the LSCA to the left common carotid artery (LCCA) was described in our previous report. ${ }^{5}$ In brief, the aortic arch was transected between the origin of the LCCA and the LSCA. The stented elephant trunk was fitted, and the LSCA was transected circumferentially, 0.5 to $1.0 \mathrm{~cm}$ distal to its origin. The proximal segment of the LSCA was sutured using 5-0 Prolene. Finally, the LSCA was anastomosed to the LCCA in an end-to-side fashion using 6-0 Prolene.

Our surgical technique for patients requiring a stented elephant trunk with total arch replacement has described in detail previously. ${ }^{6-8}$ In brief, antegrade blood perfusion of the lower body was commenced after the distal aorta, incorporating the stent-graft, was anastomosed to the distal end of the 4-branched prosthetic graft using an "open" aortic procedure. Finally, the LCCA, the proximal aortic stump, the LSCA, and the innominate artery were anastomosed to the prosthetic graft in succession using an end-

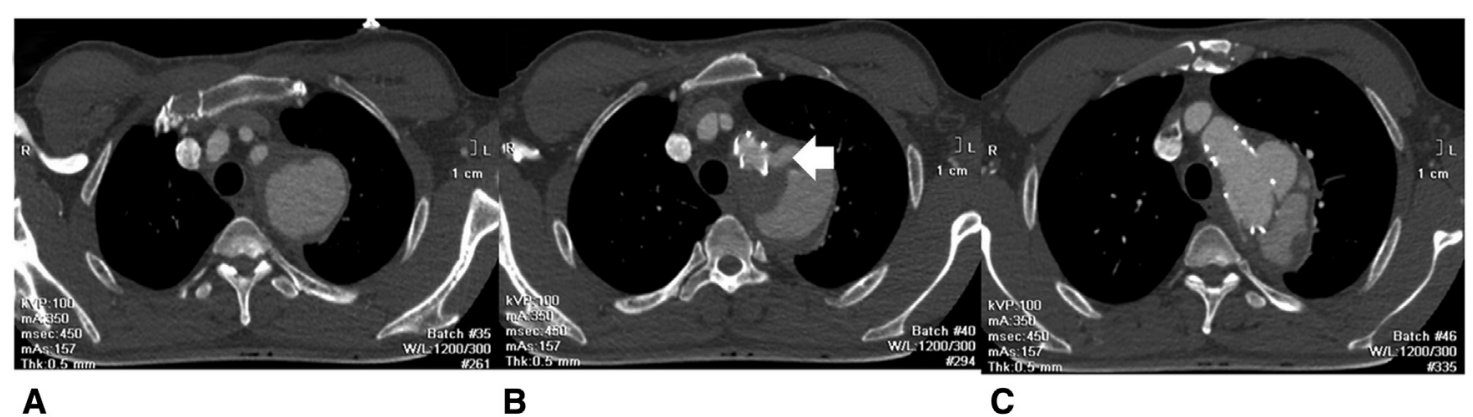

FIGURE 1. Preoperative computed tomography images of a patient with proximal type I endoleak after thoracic endovascular aortic repair (A-C). The endoleak is indicated by the white arrow (B). The distal aortic arch was involved and expanded (A-C). 
TABLE 1. Clinical profiles of patients with type Ia endoleak after TEVAR using a stented elephant trunk procedure

\begin{tabular}{|c|c|c|c|c|c|c|c|}
\hline Patient & Sex & Age, y & Symptoms and findings & $\begin{array}{c}\text { Interval, } \\
\text { mo* }^{*}\end{array}$ & Concomitant procedure & Postoperative outcome & Follow-up result \\
\hline 1 & Male & 63 & Hypertension & 84 & LSCA-LCCA transposition & Reintubation/CRRT & Follow-up death \\
\hline 2 & Male & 48 & Hypertension/diabetes & 6 & LSCA-LCCA transposition & & Alive \\
\hline 3 & Male & 48 & Hypertension & 24 & LSCA-LCCA transposition & & Follow-up death \\
\hline 4 & Male & 46 & Hypertension & 24 & LSCA-LCCA transposition & & Alive \\
\hline 5 & Male & 47 & Hypertension & 1 & LSCA-LCCA transposition & & Alive \\
\hline 6 & Male & 57 & Re-TEVAR failure & 24 & LSCA-LCCA transposition & & Follow-up death \\
\hline 7 & Male & 46 & $\begin{array}{l}\text { Hypertension/re-TEVAR } \\
\text { failure }\end{array}$ & 12 & LSCA-LCCA transposition & & Alive \\
\hline 8 & Male & 44 & Hypertension & 6 & LSCA-LCCA transposition & & Alive \\
\hline 9 & Male & 41 & Hypertension & 4 & LSCA-LCCA transposition & & Alive \\
\hline 10 & Male & 58 & Hypertension & 132 & LSCA-LCCA transposition & Pericardial drainage & Alive \\
\hline 11 & Female & 68 & Hypertension/diabetes & 3 & $\begin{array}{l}\text { AA-LSCA bypass/AA-LCCA } \\
\text { bypass }\end{array}$ & & Alive \\
\hline 12 & Male & 51 & Hypertension & 4 & AA-LAxA bypass & & Alive \\
\hline 13 & Male & 47 & Hypertension & 5 & & & Distal reintervention \\
\hline 14 & Male & 46 & Hypertension & 84 & & & Distal reintervention \\
\hline 15 & Male & 68 & Aortic root aneurysm & 48 & Bentall procedure + TAR & $\begin{array}{l}\text { Stroke/CRRT/pulmonary } \\
\text { infection }\end{array}$ & Alive \\
\hline 16 & Male & 51 & $\begin{array}{l}\text { Hypertension/diabetes/AA } \\
\text { dilation }\end{array}$ & 120 & $\mathrm{AAR}+\mathrm{TAR}$ & & Alive \\
\hline 17 & Male & 54 & $\begin{array}{l}\text { Pulmonary infection/aortic } \\
\text { root aneurysm }\end{array}$ & 1 & Bentall procedure + TAR & & Alive \\
\hline
\end{tabular}

LSCA, Left subclavian artery; $L C C A$, left common carotid artery; $C R R T$, continuous renal replacement therapy; TEVAR, thoracic endovascular aortic repair; $A A$, ascending aorta; $L A x A$, left axillary artery; TAR, total arch replacement; $A A R$, ascending aortic replacement. *Interval from the onset of aortic dissection and surgery.

to-end style. ${ }^{6,7}$ In patients with total arch replacement using preservation of autologous brachiocephalic vessels (Video 1 ), ${ }^{8}$ the neoaortic arch containing the remaining aortic arch wall involving the innominate artery and LCCA, and the trimmed stent-free sewing edge, was anastomosed to the distal end of a woven Dacron graft, which was anastomosed to the aortic root. Finally, the LSCA was anastomosed to the LCCA in an end-to-side manner.

\section{RESULTS}

\section{Operative Data}

The mean CPB time, aortic cross-clamp time, and SACP time were $169 \pm 34$ minutes (range, 88-204 minutes), $87 \pm 26$ minutes (range, 31-140 minutes), and $29 \pm 5$ minutes (range, 10-48 minutes), respectively. Concomitant procedures included LSCA-LCCA transposition in 10 patients, ascending aorta-left axillary artery bypass in 1 patient, ascending aorta-LCCA bypass plus ascending aorta-LSCA bypass in 1 patient, the Bentall procedure plus total arch replacement in 2 patients, and ascending aortic replacement plus total arch replacement in 1 patient.

\section{Morbidity and Mortality}

There were no in-hospital deaths recorded in our study cohort. In total, 13 patients required mechanical ventilation for $<24$ hours and 2 patients required mechanical ventilation for $<48$ hours. The mean duration of mechanical ventilation was $28 \pm 23$ hours (range, 6-91 hours), and the mean length of stay in the intensive care unit was $68 \pm 69$ hours (range, 9281 hours).

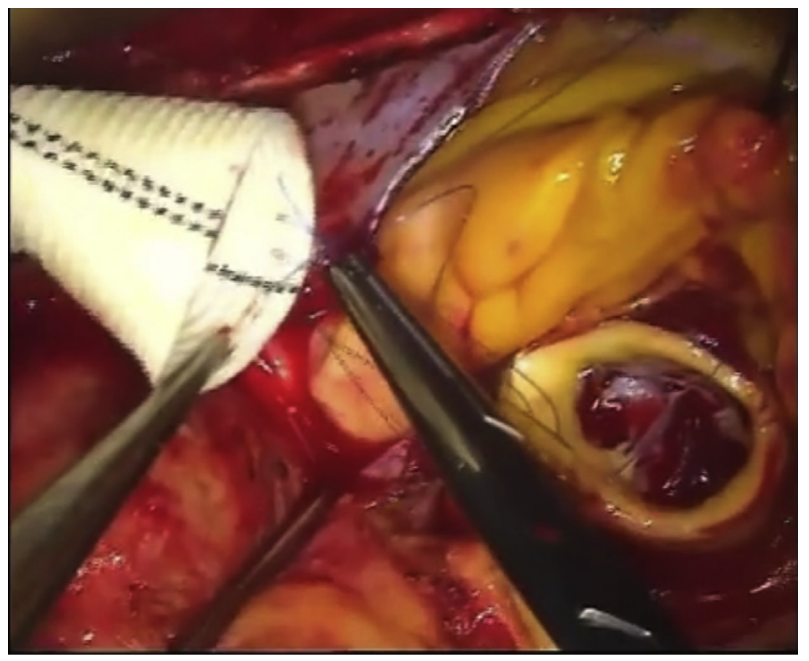

VIDEO 1. A patient with type Ia endoleak with aneurysm of the aortic arch and ascending aorta underwent total arch replacement combined with stented elephant trunk implantation with preservation of autologous brachiocephalic vessels. ${ }^{8}$ Video available at: http://www.jtcvsonline.org/ article/S0022-5223(17)32850-7/fulltext. 
One patient required reintubation after mechanical ventilation for 19 hours. Unfortunately, this patient also required continuous renal replacement therapy owing to renal failure; this patient recovered smoothly before discharge. One other case suffered stroke and renal failure; prior to discharge, he recovered from his renal failure after continuous renal replacement therapy, but the stroke did not fully heal before he left the hospital. One patient received pericardial drainage due to pericardial effusion. We did not encounter any cases of visceral ischemia or injury to the spinal cord during this study. All patients survived and were successfully discharged from hospital.

\section{Follow-up}

During a mean follow-up of $41 \pm 25$ months (range, 684 months), there were 3 deaths. One patient died at 7 months after surgery due to pulmonary infection, 1 patient died from aortic rupture 2 years after surgery, and 1 patient died from unknown causes. The patient with stroke did not fully recover during the follow-up period. TEVAR with the surgical stent-graft serving as the new proximal landing zone was successfully performed in 2 patients during follow-up. No patient experienced injury to the spinal cord or visceral malperfusion, and all patients enjoyed a normal life following hospital discharge.

\section{Imaging}

Postoperative CT angiography demonstrated that all cases of type Ia endoleak had been sealed successfully using the stented elephant trunk procedure. In all cases, the aneurysmal body was successfully excluded by the stented elephant trunk. Once the stented elephant trunk was implanted into the remaining interventional stent-graft in the distal aorta, the remaining interventional stent-graft was expanded using the stented elephant trunk. This promoted thrombosis in the false lumen of the distal aorta. In this study, complete thrombus formation around the stented elephant trunk was noted in $76.5 \%$ of patients (13 of 17 ) after surgery, extending to the diaphragmatic level in $58.8 \%$ (10 of 17), at the diaphragmatic level in $47.1 \%$ (8 of 17), and at the level of the celiac trunk in $17.6 \%$ (3 of 17) (Figure 2). In 4 patients with a patent false lumen, the diameter of the dissected descending aorta was $>60 \mathrm{~mm}$. Previous work has shown that stent-grafts fail to work properly when the false lumen is $>50 \mathrm{~mm}$ in diameter. ${ }^{9}$ Postoperative CT scanning also revealed good patency of the anastomotic site between the LSCA and the LCCA in patients undergoing the stented elephant trunk procedure with LSCA-LCCA transposition (Figure 2).

\section{DISCUSSION}

Endovascular repair of thoracic aortic disease has become a widely used technique, largely because of its invasiveness. However, complications related to endograft, such

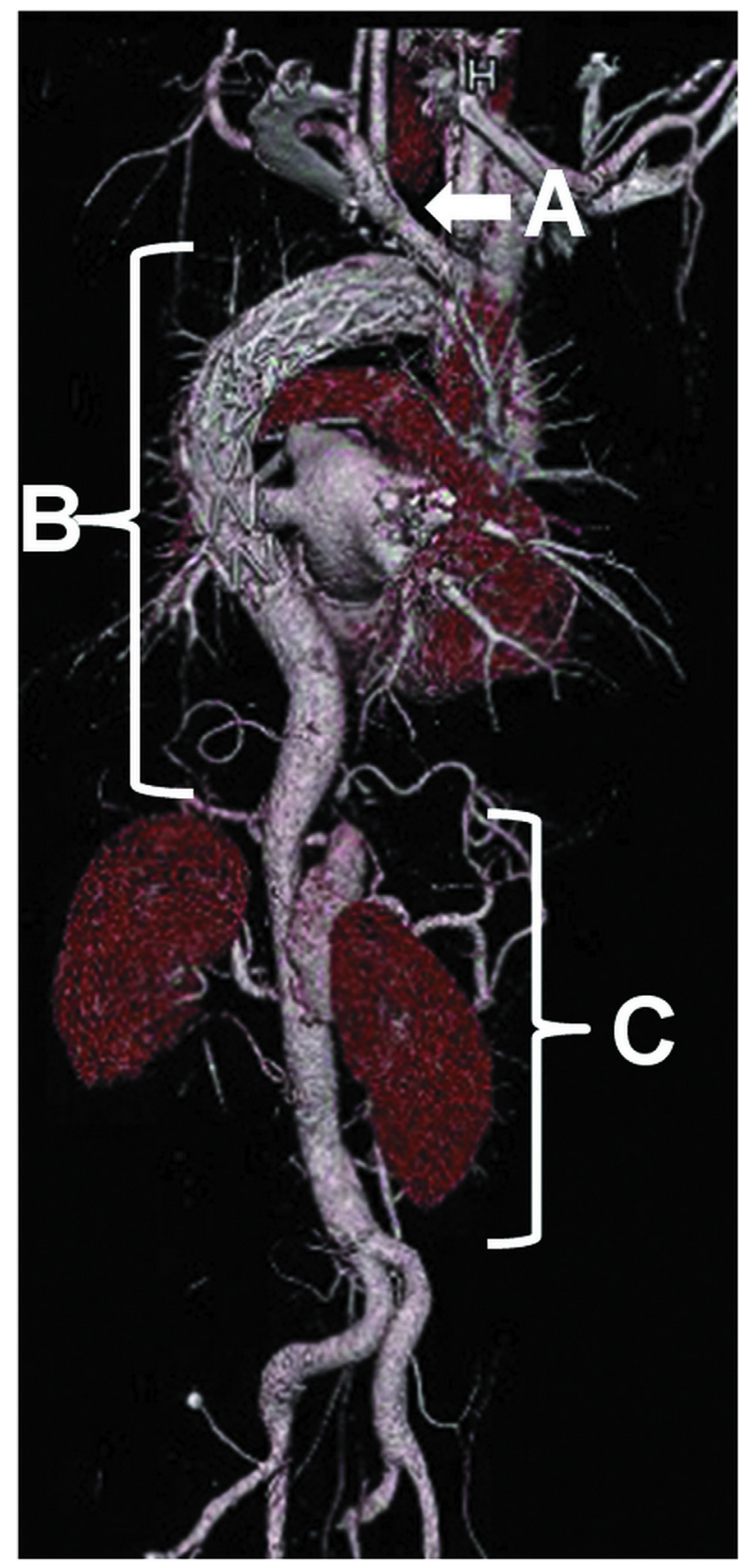

FIGURE 2. Three-dimensional reconstruction of a computed tomography scan of a patient with proximal type I endoleak at 2 years after thoracic endovascular aortic repair. A, Good patency of the anastomotic site between the left subclavian artery and the left common carotid artery. B, The descending thoracic aorta and upper abdominal aorta returned to be normal after remodeling. C, Presence of the false lumen in the abdominal aorta.

as endoleaks, retrograde type A dissection, and stroke, are not uncommon. Of these complications, endoleak is the most frequent complication after TEVAR, with a reported incidence as high as $23.3 \%$ to $32.9 \%$ of all patients with thoracic aortic disease. 
Type I endoleak results from inadequate sealing at the proximal and distal ends of the prosthesis. When identified, this condition requires immediate treatment to eliminate the leakage and prevent high sac pressure, aneurysm dilation, and aneurysm rupture. Of the 3 type I endoleak subtypes, proximal endoleaks (ie, type Ia endoleak) remains an intractable problem owing to the challenge of achieving a seal in the curved transverse aortic arch while preventing damage to the aortic arch vessels; consequently, this is considered an independent risk factor for early death. ${ }^{9}$

Several different approaches have been introduced to deal with this troublesome problem. In general, small type Ia endoleak resolves spontaneously over time and should be kept under observation during follow-up. However, a large endoleak should be treated aggressively when found. Balloon dilatation is done to correct type Ia endoleak by securing the proximal attachment sites of the endograft to the native aorta. If necessary, an additional bare metal stent or cuff is implanted proximally. To extend beyond the LSCA or even the LCCA, debranching of the aortic vessels is required to increase the length of the landing zone in patients with an inadequate proximal neck ${ }^{10}$; however, unsatisfactory results have been reported in patients treated with the hybrid technique. ${ }^{11,12}$ Moreover, the LCCA, or even the innominate artery needs to be debranched (ie, total hybrid aortic arch repair) to achieve a long landing zone in patients with a type Ia endoleak. Despite a low endoleak rate, a high mortality rate was reported in patients with total hybrid aortic arch repair in contrast to partial hybrid aortic arch repair. ${ }^{13}$ Careful patient selection is crucial during total hybrid aortic arch repair. Furthermore, bypass occlusion/stenosis tends to occur in patients undergoing either complete or partial debranching. ${ }^{14}$ Some surgeons use the chimney technique to obtain an adequate proximal landing zone while maintaining perfusion of the aortic side branches in patients with a type Ia endoleak; however, it is difficult to achieve success with this technique, ${ }^{15}$ and there have been reports of adverse events, such as stroke and endoleak. ${ }^{16}$ Transcatheter embolization is another treatment option for type I endoleak ${ }^{17}$; however, the benefit of additional coil embolization remains uncertain. In some cases, a purely interventional approach is not technically feasible.

Owing to the presence of a stent in the distal aorta and the lesions encroaching on or involving the aortic arch vessels, the repair of type Ia endoleak following TEVAR remains an intractable problem. Considering the challenges for type Ia endoleak repair after TEVAR, and the encouraging outcomes arising from the use of a stented elephant trunk for treating type $\mathrm{A}^{6,18-23}$ and type $\mathrm{B}$ dissection, ${ }^{5,24-26}$ the stented elephant trunk procedure was developed to treat type Ia endoleak after TEVAR if the proximal landing zone was shorter than recommended, involving anatomic contraindications to TEVAR, continued aneurysm or pseudoaneurysm growth, aortic arch lesions, concomitant proximal aortic arch lesions, or concomitant cardiac disease. At our center, debranching of aortic arch vessels following endoluminal exclusion of the distal aortic arch and descending aorta (ie, hybrid aortic arch repair) is done only in extremely high-risk and/or older patients.

The stented elephant trunk procedure, performed with or without a concomitant procedure, is an effective surgical treatment for proximal type I endoleak following TEVAR. After LSCA-LCCA transposition or total arch replacement, the aneurysm sac is excluded or replaced by the surgical stent, and the type Ia endoleak is corrected. In this study, successful surgical open repair of type Ia endoleak was achieved in all 17 of our patients (100\% success rate). Furthermore, once the stented elephant trunk was implanted into the remaining interventional stent-graft in the distal aorta, the remaining interventional stent-graft was expanded by the stented elephant trunk to promote thrombosis in the false lumen. In this study, thrombus formation around the stented elephant trunk was observed in most patients $(76.5 \%$; 13 of 17) during follow-up. Moreover, cardiac disease, and lesions of the transverse arch and the proximal aortic arch, were removed simultaneously; proximal aortic arch lesions were repaired in 3 patients. In addition, the stented elephant trunk procedure prevented suture leakage due to the fragile polytetrafluoroethylene membrane and facilitated the distal anastomosis. In addition, the stented elephant trunk could serve as a new proximal landing zone for TEVAR, or could create a safer and easier environment in which to sew were late thoracoabdominal aortic replacement required.

Acceptable surgical results, and postoperative outcomes, were obtained in this present patient cohort with failed TEVAR using the stented elephant trunk procedure. There were no in-hospital deaths and no severe complications. Three deaths were recorded during follow-up, including 1 from pulmonary infection, 1 from aortic rupture, and 1 from unknown causes. The surgical graft failed to work properly in patients with aortic dissection when the false lumen was $>50 \mathrm{~mm}$ in diameter. Close follow-up was required in these patients with a patent false lumen. In patients with a persistent patent false lumen, timely repair is critical to prevent aortic rupture and late death.

The present study is limited by our small number of patients, and the results are preliminary. A long-term follow-up study with a much larger cohort of patients is needed.

In summary, our data show that the stented elephant trunk procedure led to satisfactory surgical results and acceptable follow-up outcomes in all of our patients with proximal type I endoleak following TEVAR. Using this technique, we were able to surgically repair cardiac disease lesions and the proximal aortic arch, exclude or replace the aneurysm sac arising from endoleak, and promote thrombus formation 
in the distal aorta. The stented elephant trunk procedure, performed either with or without a concomitant procedure, is a viable alternative approach for proximal type I endoleak after TEVAR.

\section{Conflict of Interest Statement}

Authors have nothing to disclose with regard to commercial support.

\section{References}

1. Lee WA. Failure modes of thoracic endografts: prevention and management. $J$ Vasc Surg. 2009;49:792-9.

2. Fattori R, Montgomery D, Lovato L, Kische S, Di Eusanio M, Ince H, et al. Survival after endovascular therapy in patients with type B aortic dissection: a report from the International Registry of Acute Aortic Dissection (IRAD). JACC Cardiovasc Interv. 2013;6:876-82.

3. Patel HJ, Williams DM, Drews JD, Dasika NL, Eliason JL, Passow MC, et al. A 20-year experience with thoracic endovascular aortic repair. Ann Surg. 2014;260: 691-6; discussion 696-7.

4. Preventza O, Wheatley GH III, Ramaiah VG, Rodriguez-Lopez JA, Williams J, Olsen D, et al. Management of endoleaks associated with endovascular treatment of descending thoracic aortic diseases. J Vasc Surg. 2008;48:69-73.

5. Zhu JM, Qi RD, Chen L, Liu W, Li CN, Fan ZM, et al. Stented elephant trunk procedure with left subclavian artery transposition for acute type B dissection with distal arch involvement. J Thorac Cardiovasc Surg. 2015;150:1160-5.

6. Liu ZG, Sun LZ, Chang Q, Zhu JM, Dong C, Yu CT, et al. Should the "elephant trunk" be skeletonized? Total arch replacement combined with stented elephant trunk implantation for Stanford type A aortic dissection. J Thorac Cardiovasc Surg. 2006;131:107-13.

7. Sun L, Qi R, Chang Q, Zhu J, Liu Y, Yu C, et al. Surgery for Marfan patients with acute type A dissection using a stented elephant trunk procedure. Ann Thorac Surg. 2008;86:1821-5.

8. Zhu JM, Qi RD, Chen L, Liu W, Li CN, Fan ZM, et al. Surgery for acute type A dissection using total arch replacement combined with stented elephant trunk implantation: preservation of autologous brachiocephalic vessels. J Thorac Cardiovasc Surg. 2015;150:101-5.

9. Khoynezhad A, Donayre CE, Smith J, Kopchok GE, Walot I, White RA. Risk factors for early and late mortality after thoracic endovascular aortic repair. J Thorac Cardiovasc Surg. 2008;135:1103-9. 1109.e1-4.

10. Lipsitz E, Michler RE, Neragi-Miandoab S. Hybrid arch debranching and proximal endograft extension to repair a type I endoleak after endovascular thoracic aneurysm repair. Ann Vasc Surg. 2014;28:740.e7-12.

11. Bünger CM, Kische S, Liebold A, Leissner M, Glass A, Schareck W, et al. Hybrid aortic arch repair for complicated type B aortic dissection. J Vasc Surg. 2013;58: 1490-6.

12. Cochennec F, Tresson P, Cross J, Desgranges P, Allaire E, Becquemin JP. Hybrid repair of aortic arch dissections. J Vasc Surg. 2013;57:1560-7.
13. Kotelis D, Geisbüsch P, Attigah N, Hinz U, Hyhlik-Dürr A, Böckler D. Total vs hemi-aortic arch transposition for hybrid aortic arch repair. J Vasc Surg. 2011;54: 1182-6.e2.

14. Geisbüsch P, Kotelis D, Müller-Eschner M, Hyhlik-Dürr A, Böckler D. Complications after aortic arch hybrid repair. J Vasc Surg. 2011;53:935-41.

15. Azevedo AI, Braga P, Rodrigues A, Ferreira N, Fonseca M, Dias A, et al. Persistent type I endoleak after endovascular treatment with chimney technique. Front Cardiovasc Med. 2016:3:32

16. Kanaoka Y, Ohki T, Maeda K, Baba T. Analysis of risk factors for early type I endoleaks after thoracic endovascular aneurysm repair. $J$ Endovasc Ther. 2017; 24:89-96.

17. Eberhardt KM, Sadeghi-Azandaryani M, Worlicek S, Koeppel T, Reiser MF, Treitl M. Treatment of type I endoleaks using transcatheter embolization with onyx. J Endovasc Ther. 2014;21:162-71.

18. Sun L, Qi R, Zhu J, Liu Y, Zheng J. Total arch replacement combined with stented elephant trunk implantation: a new "standard" therapy for type A dissection involving repair of the aortic arch? Circulation. 2011;123:971-8.

19. Sun LZ, Qi RD, Chang Q, Zhu JM, Liu YM, Yu CT, et al. Is total arch replace ment combined with stented elephant trunk implantation justified for patient with chronic Stanford type A aortic dissection? J Thorac Cardiovasc Surg. 2009; 138:892-6.

20. Sun LZ, Qi RD, Chang Q, Zhu JM, Liu YM, Yu CT, et al. Surgery for acute type A dissection using total arch replacement combined with stented elephant trunk implantation: experience with 107 patients. J Thorac Cardiovasc Surg. 2009;138: 1358-62.

21. Ma WG, Zhang W, Zhu JM, Ziganshin BA, Zhi AH, Zheng J, et al. Longterm outcomes of frozen elephant trunk for type A aortic dissection in patients with Marfan syndrome. J Thorac Cardiovasc Surg. 2017:154: 1175-89.e2.

22. Ma WG, Zhang W, Wang LF, Zheng J, Ziganshin BA, Charilaou P, et al. Type A aortic dissection with arch entry tear: surgical experience in 104 patients over a 12-year period. J Thorac Cardiovasc Surg. 2016;151:1581-92.

23. Ma WG, Zheng J, Zhang W, Sun K, Ziganshin BA, Wang LF, et al. Frozen elephant trunk with total arch replacement for type A aortic dissections: does acuity affect operative mortality? J Thorac Cardiovasc Surg. 2014;148: 963-72.

24. Chen L, Qi RD, Liu W, Li CN, Zhang N, Zhu JM, et al. Repair of complicated chronic type B dissection with distal aortic arch involvement using left subclavian artery transposition with implantation of a stented elephant trunk. Thorac Cardiovasc Surg. 2017;65:99-104.

25. Sun L, Zhao X, Chang Q, Zhu J, Liu Y, Yu C, et al. Repair of chronic type B dissection with aortic arch involvement using a stented elephant trunk procedure Ann Thorac Surg. 2010;90:95-100.

26. Zhao HP, Zhu JM, Ma WG, Zheng J, Liu YM, Sun LZ. Total arch replacement with stented elephant trunk technique for acute type B aortic dissection involving the aortic arch. Ann Thorac Surg. 2012;93:1517-22.

Key Words: endoleak, stented elephant trunk, subclavian artery transposition, thoracic endovascular aortic repair 